\section{Microbial colonization patterns predict the outcomes of surgical treatment of intrabony defects}

\author{
Heitz-Mayfield L, Tonetti MS, Cortellini P, Lang NP on behalf of European Research \\ Group on Periodontology (ERGOPERIO)*. Microbial colonization patterns predict \\ the outcomes of surgical treatment of intrabony defects. J Clin Periodontol 2006; 33: \\ 62-68. doi: 10.1111/j.1600-051X.2005.00872.x.
}

\begin{abstract}
Aim: To explore the impact of bacterial load and microbial colonization patterns on the clinical outcomes of periodontal surgery at deep intrabony defects.

Materials and Methods: One hundred and twenty-two patients with advanced chronic periodontitis and at least one intrabony defect of $>3 \mathrm{~mm}$ were recruited in 10 centres. Before recruitment, the infection control phase of periodontal therapy was completed. After surgical access and debridement, the regenerative material was applied in the test subjects, and omitted in the controls. At baseline and 1 year following the interventions, clinical attachment levels (CAL), pocket probing depths (PPD), recession (REC), full-mouth plaque scores and full-mouth bleeding scores were assessed. Microbial colonization of the defect-associated pocket was assessed using a DNA-DNA checkerboard analysis.

Results: Total bacterial load and counts of red complex bacteria were negatively associated with CAL gains 1 year following treatment. The probability of achieving above median CAL gains ( $>3 \mathrm{~mm}$ ) was significantly decreased by higher total bacterial counts, higher red complex and $T$. forsythensis counts immediately before surgery.

Conclusions: Presence of high bacterial load and specific periodontal pathogen complexes in deep periodontal pockets associated with intrabony defects had a significant negative impact on the 1 year outcome of surgical/regenerative treatment.
\end{abstract}

\author{
Lisa Heitz-Mayfield ${ }^{1}$, \\ Maurizio S. Tonetti ${ }^{2}$, \\ Pierpaolo Cortellini' \\ Niklaus P. Lang ${ }^{1}$ on behalf of \\ European Research Group on \\ Periodontology (ERGOPERIO)*
}

${ }^{1}$ Department of Periodontology and Fixed Prosthodontics, University of Berne, Berne, Switzerland; ${ }^{2}$ Department of Periodontology, University of Connecticut Health Center, CT, USA

Key words: clinical trial; human; microbiota; periodontal regeneration; periodontitis.

Accepted for publication 13 October 2005
In spite of the availability of multiple efficacious techniques and biological principles, periodontal regeneration of intrabony defects remains a clinical challenge (Cortellini \& Tonetti 2000, Trombelli et al. 2002, Needleman et al. 2002, Murphy \& Gunsolley 2003). Multiple recent studies have attempted to improve outcomes by studying novel combinations of current materials (Francetti et al. 2004, Hou et al. 2004, Vouros et al. 2004, Minenna et al. 2005), or by testing the adjunctive ben-

*Patrick Adriaens, Dominik Dubravec, Alberto Fonzar, Ioannis Fourmousis, Giulio Rasperini, Roberto Rossi, Maurizio Silvestri, Heinz Topoll, Beat Wallkamm and Michael Zybutz, Private periodontal practice. efits of lasers (Sculean et al. 2004). Since the seminal work of Rosling et al. (1976) and Nyman et al. (1977), the impact of bacterial plaque on healing after surgical treatment of intrabony defects has been well recognized. Early work on regeneration with barrier membranes established a negative association between plaque control and clinical attachment level gain (Tonetti et al. 1993, 1995). Shortly after, Machtei et al. (1994) reported the detrimental effect of the persistence of specific periodontal pathogens in the pockets to be regenerated. Several studies have indicated that bleeding on probing (at the site and expressed as percentage of bleeding sites in the mouth of the patient), a clinical estimation of the persistence of periodontal pathogens, has a negative impact on clinical attachment level (CAL) gain (Tonetti et al. 1993, 1996). In more recent years, evidence has expanded and indicates that the presence of a pathogenic flora at the regenerated site or in the oral cavity of the patient before, during or after periodontal regeneration is associated with sub-optimal outcomes (Nowzari et al. 1995, De Sanctis et al. 1996, Zucchelli et al. 1997, Smith MacDonald et al. 1998, Rudiger et al. 2003). The importance of such pathogenic flora has been further emphasized by studies indicating that suppression of local microbiota with local antibiotic delivery at the wound site at the time of periodontal regeneration gives improved outcomes (Sander et al. 
1994, Zucchelli et al. 1999, Yoshinari et al. 2001, Stavropoulos et al. 2003).

In a series of multicentre clinical trials on periodontal regeneration, a significant centre effect has been constantly detected (Tonetti et al. 1998, Cortellini et al. 2001, Tonetti et al. 2002, Tonetti et al. 2004). In fact, in these trials centre variability has been the single most important factor representing three to five times the magnitude of the benefit arising from the application of a specific regenerative technique. Current hypotheses to explain centre variability include inconsistency in patient population, clinical setting, clinician experience and different abilities to suppress the periodontal microflora in the initial, causerelated phase of periodontal therapy.

This paper reports a secondary analysis of a randomized controlled clinical trial designed to compare, in a multicentre study, the clinical outcomes obtained following treatment of intrabony defects with papilla preservation flap surgery with or without application of a bioresorbable membrane in combination with a bone replacement graft. This analysis explores the impact of the microbial colonization patterns in the subgingival plaque on the clinical outcomes 1 year after treatment. Data indicated that counts but not proportions of periodontal pathogens were significantly associated with the clinical outcomes.

\section{Material and Methods \\ Experimental design}

This parallel group, randomized, multicentre and controlled clinical trial was designed to compare the efficacy of two treatment modalities in intrabony periodontal defects. The test treatment consisted of access of the defect with papilla preservation flaps (Cortellini et al. 1995, Cortellini et al. 1999), surgical debridement and application of a bovine bone replacement graft to overfill the defect (Bio-Oss $\left.{ }^{(}\right)$, Geistlich AG, Wohlhusen, Switzerland) and a collagen membrane, previously adapted to the local anatomy, positioned on top of the graft material (Bio-Gide ${ }^{(}$, Geistlich AG). The same procedure was performed in the control group except for the omission of the application of the regenerative materials. A single defect was treated in each patient. Clinical outcomes were evaluated at 1 year. This investigation was performed at 10 periodontal practices constituting a practice-based research network. Centres were located in Belgium, Germany, Greece, Italy, Switzerland, the United Kingdom and the United States of America. Details of the experimental design, calibration, randomization, surgical procedures and post-surgical follow-up have been reported in a companion paper (Tonetti et al. 2004).

\section{Subject population}

Inclusion and exclusion criteria were as previously reported (Tonetti et al. 1998, Cortellini et al. 2001, Tonetti et al. 2002). In brief, patients younger than 21 years, with uncontrolled or poorly controlled diabetes, unstable or life threatening conditions, requiring antibiotic prophylaxis or heavy smokers (more than 20 cigarettes/day) were excluded (Tonetti et al. 1995). Only patients with a diagnosis of severe periodontitis previously treated by oral hygiene instructions and scaling and root planing were invited to participate. These subjects had to present with full mouth plaque scores (FMPS) and/or full mouth bleeding scores (FMBS) $<25 \%$ at study baseline (following completion of the initial periodontal treatment phase) (Tonetti et al. 1993, Tonetti et al. 1996). The patients were informed in detail about the possible risks and benefits and were asked to give their consent to the trial. The joint ethics committee of the Eastman Dental Institute, University College London, had previously approved the study protocol.

\section{Pre-treatment}

All subjects received initial periodontal therapy aimed at controlling periodontal infection in the dentition prior to the experimental phase. Initial treatment consisted of patient motivation, oral hygiene instructions and scaling and root planing with local anaesthesia. When indicated, clinicians supplemented mechanical debridement with antiseptics and/or antimicrobials. Subjects were required to present with FMPS and/or FMBS $<25 \%$ at study baseline. At study baseline, clinical measures and subgingival microbial samples were obtained.

\section{Clinical measures}

Before anaesthesia, the following clinical parameters were evaluated on the day of the surgical procedure and 1 year later. FMPS were recorded as the percentage of total surfaces (four aspects per tooth) that revealed the presence of plaque (O'Leary et al. 1972). Bleeding on probing from the bottom of the pocket was assessed dichotomously at a force of $0.3 \mathrm{~N}$ with a manual pressure sensitive probe (Brodontic $\left.{ }^{(}\right)$probe equipped with a PCP-UNC 15 tip, Hufriedy, Rotterdam, the Netherlands). FMBS were then calculated.

Probing pocket depth (PPD) and recession of the gingival margin (REC) were recorded to the nearest millimeter with a manual pressure sensitive probe by trained investigators at the deepest location of the selected intrabony defect site. All measurements were taken with a pressure sensitive manual periodontal probe at $0.3 \mathrm{~N}$ (Brodontic ${ }^{\circledR}$ probe equipped with a PCP-UNC 15 tip, Hufriedy). Clinical attachment levels (CAL), calculated as the sum of PPD and REC, were the primary outcome variable.

\section{Microbial samples}

At study baseline, subgingival microbial samples were obtained from the deepest site in each quadrant, and in addition from the single intrabony defect site to be surgically treated, resulting in a total of five plaque samples per patient. If the intrabony defect site was also the deepest site in the quadrant, then the next deepest site was nominated as the "deepest site" in the quadrant. Following removal of supragingival plaque (after evaluating FMPS but before performing other clinical measurements), subgingival plaque samples were obtained using sterile Gracey curettes. The samples were placed in separate Eppendorf tubes containing $0.15 \mathrm{~mL}$ TE $(10 \mathrm{mM}$ TrisHCL, $1 \mathrm{mM}$ EDTA, pH 7.6), and $0.15 \mathrm{M} \mathrm{NaOH}$ was added. The samples were sent to the laboratory at the University of Berne, Switzerland where they were analysed using the checkerboard DNA-DNA hybridization technique for the presence and levels of 40 subgingival species (Socransky et al. 1994).

\section{Enumeration of organisms using "checkerboard" DNA-DNA hybridization}

The samples were lysed and neutralized using $0.8 \mathrm{~mL} 5 \mathrm{M}$ ammonium acetate. The released DNA was placed into the extended slots of a Minislot (Immunetics, Cambridge, MA, USA), concentrated onto a nylon membrane (Boehringer 
Mannheim, Indianapolis, IN, USA) by vacuum and fixed to the membrane by exposure to ultraviolet light (Stratalinker 1800, Stratagene, La Jolla, CA, USA). Digoxigenin-labelled, whole genomic DNA probes were prepared using a random primer technique (Feinberg \& Vogelstein 1983). Forty reference bacterial strains were used for the preparation of DNA probes (Socransky et al. 1994). The membranes were pre-hybridized at $42^{\circ} \mathrm{C}$ for $1 \mathrm{~h}$ in $50 \%$ formamide, $5 \times \mathrm{SCC}, 1 \%$ casein (Sigma, Basel, Switzerland), $5 \times$ Denhardt's reagent, $25 \mathrm{mM}$ sodium phosphate $(\mathrm{pH} 6.5)$ and $0.5 \mathrm{mg} / \mathrm{mL}$ yeast RNA (Boehringer Mannheim). Each membrane was placed into a Miniblotter 45 (Immunetics) with the membrane turned at $90^{\circ}$ to its original orientation. The probes and hybridization buffer were placed in individual lanes of the Miniblotter and the whole apparatus was placed in a sealed plastic bag. Membranes were hybridized for $16-18 \mathrm{~h}$ at $42^{\circ} \mathrm{C}$ in a hybridizing solution containing $45 \%$ formamide, $5 \times \mathrm{SSC}, 1 \times$ Denhardt's reagent, $20 \mathrm{mM} \mathrm{Na}$ phosphate $(\mathrm{pH} 6.5)$, $0.2 \mathrm{mg} / \mathrm{mL}$ yeast RNA, $20 \mathrm{ng} / \mathrm{mL}$ of labelled probe, $10 \%$ dextran sulfate and $1 \%$ casein. Membranes were washed at low stringency to remove loosely bound probe and then at high stringency $\left(68^{\circ} \mathrm{C}\right.$, $0.1 \times \mathrm{SSC}, 0.1 \% \mathrm{SDS}, 20 \mathrm{~min}$, twice).

To detect hybrids, membranes were blocked and incubated with a 1:20,000 dilution of anti-digoxigenin antibody conjugated with alkaline phosphatase using the modification described by Engler-Blum et al. (1993). After washing, the membranes were incubated in AttoPhos substrate (Amersham Life Science, Arlington Heights, IL, USA) for $16-18 \mathrm{~h}$ at room temperature and signals were detected using the Storm Fluorimager (Molecular Dynamics, Sunnyvale, CA, USA). Two lanes of each membrane contained standards at concentrations of $10^{5}$ and $10^{6}$ cells of each species. The sensitivity of the assay was adjusted to permit detection of $10^{4}$ cells of a given species by adjusting the concentration of each DNA probe. Signals were evaluated using the Storm Fluorimager and converted to absolute counts by comparison with the standards on the same membrane. Failure to detect a signal was recorded as zero.

\section{Post-surgical instructions and infection control}

Post-operative pain and oedema were controlled with tablets of either $600 \mathrm{mg}$ ibuprofen or $500 \mathrm{mg}$ acetaminophen. A course of doxycycline $200 \mathrm{mg}$ /day was prescribed for the first post-operative week. Patients were instructed to rinse twice daily with $0.12 \%$ chlorhexidine and to use modified oral hygiene procedures in the treated area for the first four post-operative weeks. They were instructed to start gentle wiping of the operated dento-gingival area with a post-surgical toothbrush (Vitis Surgical, Dentaid SA, Barcelona, Spain) soaked in a $0.12 \%$ chlorhexidine solution from the third post-operative day. No interdental cleaning was allowed in the treated area during the first four postoperative weeks. Smokers were asked to limit and possibly avoid smoking. Sutures were removed after 1 week. Post-surgical controls and professional tooth cleaning consisting of supragingival prophylaxis with a rubber cup and $0.2 \%$ chlorhexidine gel (Plak-Out gel, Hawe-Neos, Switzerland) were performed at weeks 1, 2, 3, 4, 6 and 8 . All patients were maintained in supportive care programmes and they received full mouth professional prophylaxis and calculus removal at 3,6 and 9 months as previously detailed (Tonetti et al. 1998).

\section{Data management and statistical analysis}

Data were entered in a spreadsheet and checked for errors. The resulting database was locked and loaded in SAS format (Statistical Application Software, SAS Institute, Cary, NC, USA). All calculations and analyses were performed using SAS Version 8.2. Data are expressed as means $\pm \mathrm{SD}$. All analyses were made using the patient as the unit for analysis. Unbalances in the test and control groups arising from the randomization process were evaluated using the unpaired $t$-test for continuous variables and the $\chi^{2}$ test for categorical variables. Each patient contributed one plaque sample from the pocket at the intrabony defect site. The significance of differences in levels and prevalence of the 40 tested species at the intrabony defect sites and the deepest site in each quadrant were determined using the Bonferroni $t$-test and the Mann-Whitney test. The significance of differences at intrabony defects between smokers and non-smokers was also determined using the Bonferroni $t$-test and the Mann-Whitney test. Significance was set at $p=0.05$ after adjusting for multiple comparisons (Socransky et al. 1991).
The significance of the microbiological parameters on the outcome variable CAL gain was estimated by constructing generalized linear models using the SAS GLM procedure (Tonetti et al. 2004). Final models were selected by elimination of non-significant factors. Model diagnostics included distribution of errors and analysis of residuals. The odds of achieving a highly significant clinical outcome (CAL gains of $>3 \mathrm{~mm}$ ) at sites colonized by high total bacterial counts, counts of red complex species and counts of individual red complex species were evaluated by constructing logistical models that included a treatment effect and patient- and defect-associated covariates (Tonetti et al. 1993, Tonetti et al. 1996, Falk et al. 1997, Tonetti et al. 2002, Tonetti et al. 2004). The final model was selected with a backward elimination procedure that allowed factors to remain in the model whenever their significance was $p=0.1$. For all other analyses the $\alpha$ error was set at 0.05 .

\section{Results \\ Patient retention and missing data}

A total of 122 subjects were entered, randomized and treated. During the 1 year period, two subjects were lost to follow-up: one test and one control patient. Complete observations were available for 120 subjects: 61 tests and 59 controls. This represented $98.4 \%$ of entered patients. Microbiological data were available for 58 test and 58 control subjects. All analyses in this report were performed on the 116 patients with available microbiological data.

\section{Subject and defect characteristics at baseline}

Subject and defect characteristics at baseline are displayed in Table 1. No significant differences between test and control patients were observed for any of the subject or defect characteristics.

\section{Baseline microbiology}

Counts and proportion of bacterial complexes, as described by Socransky et al. (1998), associated with the experimental defect are displayed in Table 2. No significant differences were observed between the microbiota of the intrabony defects and the microbiota of the mouth as assessed by the analysis of the four deepest sites per quadrant (Fig. 1). The 
Table 1. Patient and defect characteristics for test and control groups at baseline $(N=116)$

\begin{tabular}{lccc}
\hline Variable & Test & Control & $\begin{array}{c}\text { Significance } \\
p \text {-value }\end{array}$ \\
\hline Subject number & & & - \\
Age (years) & 58 & 58 & 0.7424 \\
Gender (\% females) & $49.5 \pm 11.3$ & $51 \pm 10.5$ & 0.7042 \\
Smokers (\%, <20 cigarettes/day) & $58 \%$ & $62 \%$ & 0.6960 \\
Antibiotic during initial therapy & $36.2 \%$ & $32.8 \%$ & 0.3443 \\
FMPS (\%) & $44.8 \%$ & $36.2 \%$ & 0.8289 \\
FMBS (\%) & $11.9 \pm 7$ & $11.6 \pm 8.4$ & 0.3537 \\
PPD (mm) & $9.4 \pm 6.9$ & $10.6 \pm 7.3$ & 0.8140 \\
CAL (mm) & $7.9 \pm 1.6$ & $7.9 \pm 1.5$ & 0.6820 \\
CEJ-BD (mm) & $9.8 \pm 1.8$ & $10 \pm 2.2$ & 0.6975 \\
Intrabony component (mm) & $10.2 \pm 2.5$ & $10.4 \pm 2.7$ & 0.5957 \\
Predominantly one wall (\%) & $5.7 \pm 1.9$ & $5.9 \pm 2.3$ & \\
Predominantly two walls (\%) & $22.4 \%$ & $24.6 \%$ & 0.9129 \\
Predominantly three walls (\%) & $53.5 \%$ & $54.4 \%$ & $*$ \\
\hline
\end{tabular}

*Defect wall morphology (Mantel-Haenszel $\chi^{2}$ ).

FMPS, full mouth plaque scores; FMBS, full mouth bleeding scores; PPD, probing pocket depth; CAL, clinical attachment levels.

Table 2. Counts and proportion of bacterial complexes associated with intrabony defect at baseline

\begin{tabular}{lccc}
\hline & control $(N=58)$ & test $(N=58)$ & Significance, $p$ \\
\hline & Bacterial counts $\left(\times 10^{5}\right)$ & & \\
Total counts & $160 \pm 207$ & $97 \pm 114$ & 0.0433 \\
Blue complex Actinomyces spp. & $21 \pm 32$ & $14 \pm 19$ & 0.1368 \\
Purple complex & $10 \pm 18$ & $6 \pm 11$ & 0.1910 \\
Yellow complex & $14 \pm 19$ & $8 \pm 11$ & 0.0647 \\
Green complex & $25 \pm 31$ & $15 \pm 19$ & 0.0753 \\
Orange complex & $44 \pm 73$ & $28 \pm 37$ & 0.1827 \\
Red complex & $28 \pm 80$ & $12 \pm 27$ & 0.1661 \\
Others & $28 \pm 31$ & $19 \pm 29$ & 0.1031 \\
Actinobacillus actinomycetemcomitans & $7 \pm 14$ & $4 \pm 5$ & 0.0993 \\
& Proportions $(\%)$ & & \\
Blue complex Actinomyces spp. & $14 \pm 17$ & $15 \pm 16$ & 0.7784 \\
Purple complex & $5 \pm 5$ & $5 \pm 5$ & 0.9636 \\
Yellow complex & $9 \pm 9$ & $9 \pm 8$ & 0.8597 \\
Green complex & $15 \pm 10$ & $14 \pm 7$ & 0.6642 \\
Orange complex & $24 \pm 12$ & $30 \pm 18$ & 0.0246 \\
Red complex & $15 \pm 21$ & $10 \pm 12$ & 0.0923 \\
Others & $19 \pm 14$ & $17 \pm 11$ & 0.5750 \\
A. actinomycetemcomitans & $6 \pm 8$ & $6 \pm 6$ & 0.7750 \\
\hline
\end{tabular}

prevalence of suspected periodontal pathogens at intrabony defect sites was high; 68\% Porphyromonas gingivalis, 45\% Treponema denticola, 49\% T. socranskii, $71 \%$ Prevotella intermedia, 88\% Fusobacerium nucleatum and $93 \%$ Actinobacillus actinomycetemcomitans.

While heavy smokers (>20 cigarettes/day) were excluded from this study, subjects who smoked had greater proportions of 'orange complex' species identified at intrabony defect sites compared with non-smokers (32.4 \pm $16.7 \%$ versus $23.9 \pm 13.3 \%, p<0.05)$.

\section{Clinical Outcomes}

In the control group, CAL changes between baseline and 1 year were may be associated with the bacterial counts.

The impact of baseline "red complex" counts and proportions is displayed in Table 4. Red complex counts but not proportions had a significant negative impact on 1 year CAL gains after correcting for known covariates.

The probability of obtaining CAL gains greater than the observed median response $(3 \mathrm{~mm})$ was modeled by logistic regression analyses. Bacterial parameters were inserted into the models along with treatment effect, patient factors such as gender, smoking status, FMPS and FMBS and defect factors such as flap design, defect morphology, depth of the intrabony component of the defect and baseline PPD. A backward elimination process was applied setting the significance for keeping variables in the model at 0.1 . The table indicates that total counts, red complex counts and $T$. forsythensis counts had a significant but small negative effect on the probability to gain more than $3 \mathrm{~mm}$ of CAL. Counts of $P$. gingivalis, $T$. denticola and other complexes, as well as proportion of complexes or specific pathogens did not have a significant effect.

\section{Discussion}

The results of this study support the notion that the presence of high bacterial counts and the persistence of specific bacterial pathogens in the pocket before surgical treatment are negatively associated with the outcome of treatment.

The high prevalence of $A . a$ observed at the intrabony defect sites within these patients was of particular note. A series of checks for quality control were performed in order to confirm that the signals obtained from the A.a DNA probe used were valid. This included cross-reactivity checks, validation of the source DNA within the probe and running the probe against plaque samples in healthy individuals. While the prevalence of A. $a$ was considered high, similar levels have been reported in the literature (Choi et al. 2000, Doungudomdacha et al. 2001, Papapanou et al. 2002).

The data are remarkable given the high levels of plaque control and control of clinical inflammation achieved during a carefully performed cause-related phase of periodontal therapy completed to the satisfaction of the treating perio- 

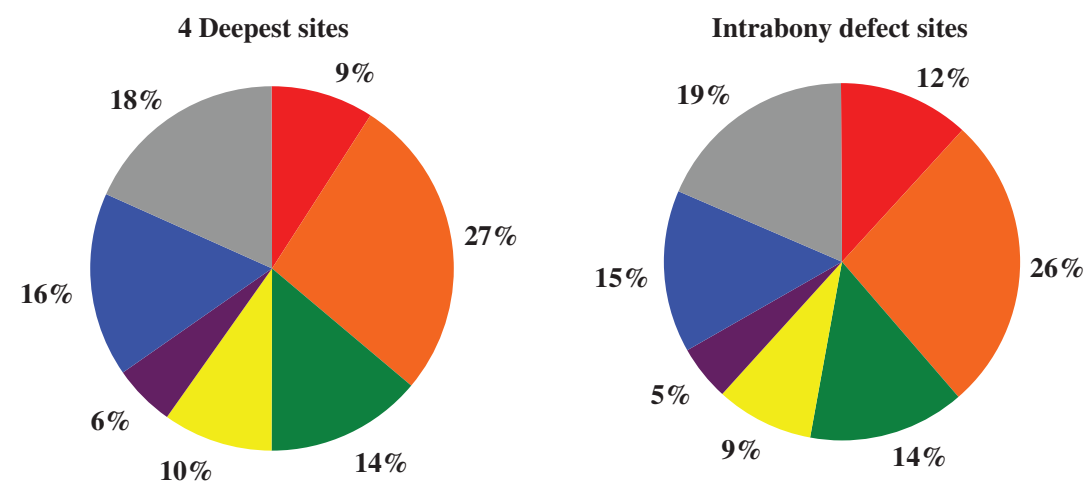

Fig. 1. Pie diagrams of the percentage of the total DNA probe count of the microbial complexes described by Socransky et al. (1998). The left pie diagram represents subgingival plaque samples from the deepest site in each quadrant. Four sites per patient were pooled to provide a mean value for each patient. The right pie diagram represents the subgingival plaque samples from the intrabony defect sites $(N=116)$.

Table 3. Effect of baseline total bacterial counts at intrabony defect on 1 year CAL gain

\begin{tabular}{lcr}
\hline Parameter & Estimate & Significance, $p$ \\
\hline \multicolumn{1}{c}{ Model without microbiological } \\
Centre (best versus worst) & $1.65 \pm 0.85$ & \\
Treatment (test versus control $)$ & $0.72 \pm 0.28$ & $\left.0.0006, R^{2}=0.43\right)$ \\
Baseline FMPS & $0.05 \pm 0.03$ & 0.0116 \\
Baseline FMBS & $-0.11 \pm 0.04$ & 0.0574 \\
Baseline PPD & $0.54 \pm 0.13$ & 0.0156 \\
& Model with total bacterial counts $\left(p=0.0002, R^{2}=0.46\right)$ & \\
Centre & $2.15 \pm 0.82$ & 0.0001 \\
Treatment (test versus control) & $0.62 \pm 0.28$ & 0.0101 \\
Baseline FMPS & $0.05 \pm 0.03$ & 0.0274 \\
Baseline FMBS & $-0.09 \pm 0.04$ & 0.0612 \\
Baseline PPD & $0.57 \pm 0.12$ & 0.0408 \\
Total bacterial counts $\left(\times 10^{5}\right)$ & $-0.002 \pm 0.001$ & $<0.0001$ \\
\end{tabular}

FMPS, full mouth plaque scores; FMBS, full mouth bleeding scores; PPD, probing pocket depth; CAL, clinical attachment levels.

Table 4. Effect of baseline "red complex" counts and proportions on 1 year CAL gain

\begin{tabular}{|c|c|c|}
\hline Parameter & Estimate & Significance, $p$ \\
\hline \multicolumn{3}{|c|}{ Red complex counts $\left(p=0.0001, R^{2}=0.47\right)$} \\
\hline Centre (best versus worst) & $1.8 \pm 0.9$ & 0.0497 \\
\hline Treatment (test versus control) & $0.71 \pm 0.28$ & 0.0135 \\
\hline Baseline FMPS & $0.03 \pm 0.02$ & 0.2233 \\
\hline Baseline FMBS & $-0.08 \pm 0.04$ & 0.0594 \\
\hline Baseline PPD & $0.6 \pm 0.13$ & $<0.0001$ \\
\hline Red complex counts $\left(\times 10^{5}\right)$ & $-0.007 \pm 0.003$ & 0.0114 \\
\hline \multicolumn{3}{|c|}{ Red complex proportions $\left(p=0.0014, R^{2}=0.44\right)$} \\
\hline Centre & $1.8 \pm 0.9$ & 0.0602 \\
\hline Treatment (test versus control) & $0.8 \pm 0.3$ & 0.0112 \\
\hline Baseline FMPS & $0.05 \pm 0.03$ & 0.0830 \\
\hline Baseline FMBS & $-0.12 \pm 0.05$ & 0.0111 \\
\hline Baseline PPD & $0.55 \pm 0.14$ & $<0.0001$ \\
\hline Red complex proportions & $0.002 \pm 0.01$ & 0.8661 \\
\hline
\end{tabular}

FMPS, full mouth plaque scores; FMBS, full mouth bleeding scores; PPD, probing pocket depth; CAL, clinical attachment levels.

dontist and meeting current clinical practice criteria (Cortellini \& Tonetti 2005). They also imply that there may be no "clinically acceptable" level of residual periodontal infection in the context of regenerative therapy.
The deep pockets associated with the intrabony defects treated in this study clearly represent formidable challenges for suppression of the periodontal microflora and thus the high total counts and the high prevalence of residual pathogens observed following completion of cause related therapy are not unexpected. In these deep pockets periodontal debridement alone may not be sufficient to properly suppress the microbiota. Alternatively, the current standard of practice, requiring a minimum of 4-6 weeks before re-evaluation of the outcomes of the initial, causerelated phase of therapy, may allow recolonization of the defect-associated pocket with a pathogenic flora (Tonetti et al. 1995). Such recolonization may also occur during the healing phase following the surgery in spite of the meticulous post-operative regimen using a combination of antibiotics, antiseptics and professional tooth cleaning (Cortellini et al. 1993).

While heavy smokers ( $>20$ cigarettes/day) were excluded from this study and thus smoking did not show a significant effect on the clinical outcome, the observation that subjects who smoked had significantly greater proportions of pathogens in the "orange complex" than non-smokers may be of importance. A detrimental effect of smoking on the outcome of regenerative procedures has been previously documented (Tonetti et al. 1995, Mayfield et al. 1998, Stavropoulos et al. 2004) and may be in part related to a more pathogenic microflora at deep intrabony defect sites in patients who smoke.

Given the high levels of contamination of the periodontal pockets immediately before surgery, the fact that no frank infections leading to exfoliation of the bone replacement graft were observed is remarkable. Nevertheless, clinical attachment level gains of $1 \mathrm{~mm}$ or less were observed in $11 \%$ of subjects treated with the bone replacement graft and GTR membrane (Tonetti et al. 2004). It is conceivable that in some of these subjects contamination of the biomaterial following manipulation and placement in a highly contaminated wound may be responsible for the lack of a positive healing outcome.

Taken together with previous evidence, these data support the need to conduct intervention trials specifically aimed at assessing the benefit(s) of maximal suppression of the microflora at the defect-associated pocket. 
Table 5. Logistic regression analyses of microbial factors affecting the probability of obtaining CAL gains above the median $(>3 \mathrm{~mm})$

\begin{tabular}{lcc}
\hline Parameter & Odds ratio* & $95 \%$ CI. \\
\hline Total counts & 0.975 & $0.958-0.992$ \\
Counts of other complexes & Not significant & - \\
Red complex counts & 0.985 & $0.974-0.996$ \\
T. forsythensis counts & 0.975 & $0.958-0.992$ \\
Porphyromonas gingivalis counts & Not significant & - \\
T. denticola counts & Not significant & - \\
\hline
\end{tabular}

*Results of multivariate backward elimination logistic regression analyses including gender, smoking status, flap design, defect morphology, depth of intra-bony component of defect, treatment effect, FMPS, FMBS and baseline PPD and baseline microbial parameters in the model.

FMPS, full mouth plaque scores; FMBS, full mouth bleeding scores; PPD, probing pocket depth; CAL, clinical attachment levels.

\section{Acknowledgements}

This study was partly supported by the Accademia Toscana di Ricerca Odontostomatologica (ATRO), Firenze, Italy, the European Research Group in Periodontology (ERGOPERIO), Bern, Switzerland, and an unrestricted research grant from Geistlich AG, Switzerland. Authors had full control of the data, of the analyses and received no commercial input in the preparation of the manuscript. Authors wish to express their gratitude to Ms Regula Jordi and Ms Marianne Weibel for the competent technical assistance with the microbiological analyses and to Ms Jean Suvan for expert co-ordination of the multicentre trial from which this secondary analysis was performed.

\section{References}

Choi, B. K., Park, S. H., Yoo, Y. J., Choi, S. H., Chai, J. K., Cho, K. S. \& Kim, C. K. (2000) Detection of major putative periodontopathogens in Korean advanced adult periodontitis patients using a nucleic acid-based approach. Journal of Periodontology 9, 1387-1394.

Cortellini, P., Pini Prato, G. \& Tonetti, M. (1999) The simplified papilla preservation flap. A novel surgical approach for the management of soft tissues in regenerative procedures. International Journal of Periodontics and Restorative Dentistry 19, 589-599.

Cortellini, P., Pini-Prato, G. \& Tonetti, M. (1995) The modified papilla preservation technique. A new surgical approach for interproxymal regenerative procedures. Journal of Periodontology 66, 261-266.

Cortellini, P., Pini-Prato, G. P. \& Tonetti, M. S (1993) Periodontal regeneration of human infrabony defects. I. Clinical measures. Journal of Periodontology 64, 254-260.

Cortellini, P. \& Tonetti, M. (2000) Focus on intrabony defects: guided tissue regeneration. Periodontology 2000 22, 104-132.
Cortellini, P., Prato, G. P. \& Tonetti, M. S. (1995) The modified papilla preservation technique. A new surgical approach for interproximal regenerative procedures. Journal of Periodontology 4, 261-266.

Cortellini, P., Tonetti, M., Lang, N., Suvan, J., Zucchelli, G., Vangsted, T., Silvestri, M., Rossi, R., McClain, P., Fonzar, A., Dubravec, D. \& Adriaens, P. (2001) The simplified papilla preservation flap in the regenerative treatment of deep intrabony defects. A multicentre randomized controlled clinical trial evaluating clinical outcomes and post-operative morbidity. Journal of Periodontology $\mathbf{7 2}$, 1702-1712.

Cortellini, P. \& Tonetti, M. (2005) Clinical performance of a regenerative strategy for intrabony defects: scientific evidence and clinical experience. Journal of Periodontology 3, 341-350.

De Sanctis, M., Zucchelli, G. \& Clauser, C. J. (1996) Bacterial colonization of bioabsorbable barrier material and periodontal regeneration. Journal of Periodontology 11, 1193-2000.

Doungudomdacha, S., Rawlinson, A., Walsh, T. F. \& Douglas, C. W. (2001) Effect of nonsurgical periodontal treatment on clinical parameters and the numbers of Porphyromonas gingivalis, Prevotella intermedia and Actinobacillus actinomycetemcomitans at adult periodontitis sites. Journal of Clinical Periodontology 5, 437-445.

Engler-Blum, G., Meier, M., Frank, J. \& Muller, G. A. (1993) Reduction of background problems in non radioactive northern and Southern blot analyses enables higher sensitivity than 32P-based hybridizations. Analytical Biochemistry 210, 235-244.

Falk, H., Laurell, L., Ravald, N., Teiwik, A. \& Persson, R. (1997) Guided tissue regeneration therapy of 203 consecutively treated intrabony defects using a bioabsorbable matrix barrier. Clinical and radiographic findings. Journal of Periodontology 68, 571-581.

Feinberg, A. P. \& Vogelstein, B. (1983) A technique for radiolabeling DNA restriction endonuclease fragments to high specific activity. Analytical Biochemistry 132, 6-13.

Francetti, L., Del Fabbro, M., Basso, M., Testori, T. \& Weinstein, R. (2004) Enamel matrix proteins in the treatment of intrabony defects. A prospective 24-month clinical trial. Journal of Clinical Periodontology 31, 52-59.

Hou, L. T., Yan, J. J., Tsai, A. Y., Lao, C. S., Lin, S. J. \& Liu, C. M. (2004) Polymerassisted regeneration therapy with Atrisorb barriers in human periodontal intrabony defects. Journal of Clinical Periodontology 31, 68-74.

Machtei, E., Cho, M., Dunford, R., Norderyd, J., Zambon, J. \& Genco, R. (1994) Clinical, microbiological, and histological factors which influence the success of regenerative periodontal therapy. Journal of Periodontology 65, 154-161.

Mayfield, L. J., Söderholm, G., Hallström, H., Bratthall, G. \& Attström, R. (1998) Guided tissue regeneration for the treatment of intraosseous defects using a bioabsorbable membrane. A controlled clinical study. Journal of Clinical Periodontology 25, 585-595.

Minenna, L., Herrero, F., Sanz, M. \& Trombelli, L. (2005) Adjunctive effect of a polylactide/ polyglycolide copolymer in the treatment of deep periodontal intra-osseous defects: a randomized clinical trial. Journal of Clinical Periodontology 32, 456-461.

Murphy, K. G. \& Gunsolley, J. C. (2003) Guided tissue regeneration for the treatment of periodontal intrabony and furcation defects. A systematic review. Annals of Periodontology 8, 266-302.

Needleman, I., Tucker, R., Giedrys-Leeper, E. \& Worthington, H. (2002) A systematic review of guided tissue regeneration for periodontal infrabony defects. Journal of Periodontal Research 37, 380-388.

Nowzari, H., Matian, F. \& Slots, J. (1995) Periodontal pathogens on polytetrafluoroethylene membrane guided tissue regeneration inhibit healing. Journal of Clinical Periodontology 22, 469-474.

Nyman, S., Lindhe, J. \& Rosling, B. (1977) Periodontal surgery in plaque-infected dentitions. Journal of Clinical Periodontology 4, 240-249.

O’Leary, T. J., Drake, R. B. \& Naylor, J. E. (1972) The plaque control record. Journal of Periodontology 43, 38.

Papapanou, P. N., Teanpaisan, R., Obiechina, N. S., Pithpornchaiyakul, W., Pongpaisal, S., Pisuithanakan, S., Baelum, V., Fejerskov, O. \& Dahlen, G. (2002) Periodontal microbiota and clinical periodontal status in a rural sample in southern Thailand. European Journal of Oral Sciences 5, 345-352.

Rosling, B., Nyman, S. \& Lindhe, J. (1976) The effect of systematic plaque control on bone regeneration in infrabony pockets. Journal of Clinical Periodontology 1, 38-53.

Rudiger, S. G., Ehmke, B., Hommens, A., Karch, H. \& Flemmig, T. F. (2003) Guided tissue regeneration using a polylactic acid barrier. Part I: environmental effects on bacterial colonization. Journal of Clinical Periodontology 1, 19-25.

Sander, L., Frandsen, E. V., Arnbjerg, D., Warrer, K. \& Karring, T. (1994) Effect of local metronidazole application on perio- 
dontal healing following guided tissue regeneration. Clinical findings. Journal of Periodontology 10, 914-920.

Sculean, A., Schwarz, F., Berakdar, M., Windisch, P., Arweiler, N. B. \& Romanos, G. E. (2004) Healing of intrabony defects following surgical treatment with or without an Er: AG laser. Journal of Clinical Periodontology 31, 604-608.

Smith MacDonald, E., Nowzari, H., Contreras, A., Flynn, J., Morrison, J. \& Slots, J. (1998) Clinical and microbiological evaluation of a bioabsorbable and a nonresorbable barrier membrane in the treatment of periodontal intraosseous lesions. Journal of Periodontology 4, 445-453.

Socransky, S. S., Haffajee, A. D., Cugini, M. A., Smith, C. \& Dibart, S. (1991) Relation of counts of microbial species to clinical status at the sampled site. Journal of Clinical Periodontology 18, 766-775.

Socransky, S. S., Smith, C., Martin, L., Paster, B. J., Dewhierst, F. E. \& Levin, A. E. (1994) "Checkerboard" DNA-DNA hybridization. Biotechniques 4, 788-792.

Socransky, S. S., Haffajee, A. D., Cugini, M. A., Smith, C. \& Kent, R. L. Jr. (1998) Microbial complexes in subgingival plaque. Journal of Clinical Periodontology 25, 134-144.

Stavropoulos, A., Karring, E. S., Kostopoulos, L. \& Karring, T. (2003) Deproteinized bovine bone and gentamicin as an adjunct to GTR in the treatment of intrabony defects: a randomized controlled clinical study. Journal of Clinical Periodontology 30, 486-495.

Stavropoulos, A., Mardas, N., Herrero, F. \& Karring, T. (2004) Smoking affects the outcome of guided tissue regeneration with bioresorbable membranes: a retrospective analysis of intrabony defects. Journal of Clinical Periodontology 31, 945-950.

Tonetti, M., Pini-Prato, G. \& Cortellini, P. (1993) Periodontal regeneration of human

\section{Clinical Relevance}

Scientific rationale for study: The impact of the subgingival microflora at deep intrabony defects on the clinical attachment level gains following surgical/regenerative treatment requires investigation. infrabony defects. IV. Determinants of the healing response. Journal of Periodontology 64, 934-940.

Tonetti, M., Pini-Prato, G. \& Cortellini, P. (1995) Effect of cigarette smoking on periodontal healing following GTR in infrabony defects. A preliminary retrospective study. Journal of Clinical Periodontology 22, 229-234.

Tonetti, M., Pini-Prato, G. \& Cortellini, P. (1996) Factors affecting the healing response of intrabony defects following guided tissue regeneration and access flap surgery. Journal of Clinical Periodontology 23, 548-556.

Tonetti, M., Cortellini, P., Suvan, J., Adriaens, P., Baldi, C., Dubravec, D., Fonzar, A., Fourmousis, I., Magnani, C., Muller-Campanile, V., Patroni, S., Sanz Alonso, M., Vangsted, T., Zabalegui, I., Pini-Prato, G. \& Lang, N. (1998) Evaluation of generalizability of the added benefit of GTR in the treatment of deep intrabony defects. A phase iv multicenter randomized controlled clinical trial. Journal of Periodontology 69, 1183-1192.

Tonetti, M. S., Lang, N. P., Cortellini, P., Suvan, J. E., Adriaens, P., Dubravec, D., Fonzar, A., Fourmousis, I., Mayfield, L., Rossi, R., Silvestri, M., Tiedemann, C., Topoll, H., Vangsted, T. \& Wallkamm, B. (2002) Enamel matrix proteins in the regenerative therapy of deep intrabony defects. Journal of Clinical Periodontology 29. 317-325.

Tonetti, M. S., Cortellini, P., Lang, N. P., Suvan, J. E., Adriaens, P., Dubravec, D., Fonzar, A., Fourmousis, I., Rasperini, G., Rossi, R., Silvestri, M., Topoll, H., Wallkamm, B. \& Zybutz, M. (2004) Clinical outcomes following treatment of human intrabony defects with GTR/bone replacement material or access flap alone. A multicenter randomized controlled clinical trial.

Journal of Clinical Periodontology 31, 770-776.

Trombelli, L., Heitz-Mayfield, L. J., Needleman, I., Moles, D. \& Scabbia, A. (2002) A systematic review of graft materials and biological agents for periodontal intraosseous defects. Journal of Clinical Periodontology 29 (Suppl. 3), 117-135 discussion 160-2.

Vouros, I., Aristodimou, E. \& Konstantinidis, A. (2004) Guided tissue regeneration in intrabony periodontal defects following treatment with two bioabsorbable membranes in combination with bovine bone mineral graft. A clinical and radiographic study. Journal of Clinical Periodontology 31, 908-917.

Yoshinari, N., Tohya, T., Kawase, H., Matsuoka, M., Nakane, M., Kawachi, M., Mitani, A., Koide, M., Inagaki, K., Fukada, M. \& Noguchi, T. (2001) Effect of repeated local Minocycline administration on periodontal healing following guided tissue regeneration. Journal of Clinical Periodontology $\mathbf{3}$, 284-295.

Zucchelli, G., De Sanctis, M. \& Clauser, C. (1997) Integrated connective tissue in bioabsorbable barrier material and periodontal regeneration. Journal of Periodontology 10 996-1004.

Zucchelli, G., Sforza, N. M., Clauser, C., Cesari, C. \& De Sanctis, M. (1999) Topical and systemic antimicrobial therapy in guided tissue regeneration. Journal of Periodontology 3, 239-247.

Address:

Maurizio S. Tonetti

Department of Periodontology

University of Connecticut Health Center

263 Farmington Ave

Farmington, CT 06030

USA

E-mail: MTonetti@uchc.edu

Principal findings: High bacterial loads and high levels of red complex species may be found in deep intrabony pockets even after initial periodontal therapy, and this has a negative influence on the clinical outcome 1 year following surgical /regenerative treatment.
Practical implications: Additional antimicrobial treatment may be required prior to regeneration at intrabony defects to reduce bacterial load. Prospective intervention trials to establish the benefit(s) of maximal pre-operative microbial suppression are needed. 